\title{
Van İlinin Çaldıran İlçesinde Yetişen Bazı Tıbbi Bitkilerin Toplam Fenolik ve Flavonoid Madde Miktarlarının Belirlenmesi
}

\author{
Deniz İRTEM KARTAL ${ }^{1}$, Neşe ERAY ${ }^{2}$, Fazlı ÖZTÜRK ${ }^{3}$ \\ 1,2Van Yüzüncü Yıl Üniversitesi Fen Fakültesi Moleküler Biyoloji ve Genetik Bölümü, Van, 3Van Yüzüncü Yıl Üniversitesi Fen Fakültesi \\ Biyoloji Bölümü, Van \\ 1https://orcid.org/0000-0001-9669-5828, ${ }^{2}$ https://orcid.org/0000-0001-6387-1493, ${ }^{2}$ https://orcid.org/0000-0003-1728-7944 \\ $\bowtie$ : denizirtem@yyu.edu.tr
}

\section{ÖZET}

Çalışmanın amacı, Çaldıran/Van'da yetişen ve halk arasında sıkça tüketilen bazı tıbbi bitkilerin, toplam fenolik (TFM) ve flavonoid (TF) miktarlarının belirlenmesi ve farklı organlardan elde edilen su ekstrelerindeki olası farkların ortaya konmasıdır. Alcea pallida (Hiro) (Willd.) Waldst. \&. Kit., Rumex scutatus L. (Evelik), Mentha longifolia (L.) L. (Dağ Reyhanı), Erigeron acris L., Achillea vermicularis Trin. (Civan Perçemi) bitkileri Van/Çaldıran'dan toplanmıştır. Ekstrelerin TFM ve TF içerikleri spektrofotometrik olarak ölçülmüştür. En yüksek TFM ve TF madde $E$. acris bitkisinin tohum ekstresinden elde edilmiştir. Aynı bitkinin gövde ekstresi ve $M$. longifolia tohum ve gövde ekstreleri de yüksek fenolik ve flavonoid madde taşıyan bitki kısımları olmuştur. Sonuçta, kullanılan beş farklı bitkiden alınan çiçek, gövde ve tohum ekstrelerinin hepsinde çiçek ve/veya tohum ekstrelerinin gövde ekstrelerine göre daha verimli olduğu ortaya konmuştur. E. acris ve $M$. longifolia bitkilerinden elde edilen sonuçlar, bu bitkilerin tıbbi amaçlara uygun olarak kullanılabileceğini, hem tohum hem gövde kısımlarının yoğun fenolik ve flavonoid içerdiğini göstermiştir.

\section{Araştırma Makalesi}

Makale Tarihçesi

Geliş Tarihi : 30.10 .2019

Kabul Tarihi : 06.02.2020

\section{Anahtar Kelimeler}

Erigeron acris

Fenolik madde

Flavonoid

Mentha longifolia

Tibbi bitki

\section{Determination of Total Phenolic and Flavonoid Contents of Some Medicinal Plants Growing in Çaldıran Province of Van}

\section{ABSTRACT}

The aim of the study was to determine the total phenolic (TPC) and flavonoid (TF) contents of some medicinal plants grown in Çaldıran/Van that are frequently consumed by people and to reveal possible differences in the water extracts obtained from different organs. Alcea pallida (Willd.) Waldst. \&. Kit. Rumex scutatus L., Mentha longifolia (L.) L., Erigeron acris L., Achillea vermicularis Trin. were collected from Çaldıran/Van. TPC and TF contents of the extracts were measured spectrophotometrically. The highest TPC and TF were obtained from the seed extract of $E$. acris. Stem extracts of the same plant and the stem and seed extracts of $M$. longifolia were also the samples carrying high phenolic and flavonoids. As a result, it was shown that the flower and seed extracts of five different plants were more efficient than the stem extracts. Biochemical profiles of $E$. acris and $M$. longifolia showed that these plants can be used for medicinal purposes and both seed and stem parts contain notably high levels of phenolic and flavonoids.

\section{ResearchArticle}

$\begin{array}{ll}\text { ArticleHistory } & \\ \text { Received } & : 30.10 .2019 \\ \text { Accepted } & : 06.02 .2020\end{array}$

Keywords

Erigeron acris

Phenolics

Flavonoids

Mentha longifolia

Medicinal plant

ToCite : Kartal Dİ, Eray N, Öztürk F 2020. Van İlinin Çaldıran İlçesinde Yetişen Bazı Tıbbi Bitkilerin Toplam Fenolik ve Flavonoid Madde Miktarlarının Belirlenmesi. KSÜ Tarım ve Doğa Derg 23 (3): 611-616. DOI: 10.18016/ksutarimdoga. vi.637632.

\section{GİRIŞ}

Bitkiler binlerce yıldır olduğu gibi günümüzde de geleneksel tıbbın temelini oluşturmakta ve insanlığa her geçen gün yeni çareler sunmaya devam etmektedirler. Doğrudan bitkinin çeşitli kısımlarının veya onlardan elde edilen etken maddelerin hastalıkların tedavisinde kullanılması literatüre tıbbi 
bitki terimini kazandırmıştır. Tıbbi bitkiler, yeni ilaçların gelişmesine olanak sağlayacak terapötik fitokimyasal kaynağı olmalarından dolayı büyük bir öneme sahiptirler.

Fitokimyasallar beş sınıfa ayrılabilir, polifenoller en çok çalışılanlardır ve karotenoidler, alkaloidler, azot içeren bileşikler ve kükürt içeren bileşiklerden daha güçlü antioksidanlar olarak kabul edilirler (Mandlekar ve ark., 2006). Polifenoller, bir veya daha fazla aromatik halka içeren ve onlara bağlı bir veya daha fazla hidroksil grubu olan en az 10.000 farklı bileşikten oluşan büyük bir grubu temsil eder ( $\mathrm{Li}$ ve ark., 2014). En sik bulunan diyet polifenolleri flavonoidler ve fenolik asitlerdir (Araújo ve ark., 2011). Fenolikler, antioksidan, antimutajenik, antikarsinojenik ve gen ekspresyon modülatörü olarak birçok farklı biyokimyasal aktiviteye sahiptirler (Nakamura ve ark., 2003). Aynı zamanda bu bileşiklerin antibiyotik, antialerjenik, antiinflamatuar aktivite sergilediği, bazı kanser hücre hatlarında antipoliferatif etki gösterdiği bildirilmiştir (Tungmunnithum ve ark., 2018). Çok sayıda epidemiyolojik çalışma diyetle flavonoid alımının kardiovasküler ve karsinojenik hastalık riskini azalttığını ortaya koymuştur (Yang ve ark., 2019).

Fenolikler ve flavonoidler gibi, bitki kaynaklarından elde edilen fitokimyasalların çoğunun kanser önleme üzerinde olumlu etkisi olduğu bildirilmiştir (Kumar ve Goel, 2019; Sankaranarayanan ve ark., 2019). Tibbi bitkilerdeki yüksek fenolik ve flavonoid içeriği onların antioksidan aktiviteleri ile ilişkilidir ve bu maddeler özellikle oksidatif stresin neden olduğu yaşla ilişkili hastalıkların önlenmesinde rol alırlar (Singh, 2015). Avrupa Birliği ve bazı ülkelerde yaklaşık 100 milyon insan hala geleneksel, tamamlayıcı bitkisel ürünler kullanmakta, tıbbi bitki pazarı sürekli büyümekte ve bitki kaynaklı ürün pazarının 2020'yekadar 115 US\$ milyara ulaşacağı tahmin edilmektedir (Jamshidi-Kia ve ark., 2018). Bu pazara olan talep ağırlıklı olarak kadınlardan gelmekte ve sentetik ürünlerin yan etkilerinden doğan endişe ile yönlendirilmektedir. $\mathrm{Bu}$ nedenle, tıbbi bitkiler alanında araştırmanın önemi her zamankinden daha fazla hissedilir (Jamshidi-Kia ve ark., 2018).

Günümüzde sentetik ürünler insanoğlunu kuşatmış durumdadır. Sentetik maddelerin yan etkilerinin bulunması, bozunma parçalanma sürelerinin uzun olması, bozunma ürünlerinin zehirli olması gibi nedenlerle doğal bitkisel ürünlere talep artmaktadır (Babaoğlu ve ark., 2001; Jamshidi-Kia ve ark., 2018). Çin, Hindistan, Japonya, Pakistan ve Tayland gibi ülkelerde tıbbi bitkiler oldukça yaygındır ve nüfusun büyük bir bölümünün temel sağlık hizmetleri ihtiyaçlarını karşılamak için geleneksel pratisyen hekimlerden ve tıbbi bitkilerden faydalandığını göstermektedir. Her ne kadar bu ülkelerde modern tıp mevcut olsa da, bitkisel ilaçlar tarihi ve kültürel nedenlerle popülerliğini korumuştur (Singh, 2015).

Fenolik bileşiklerin güçlü biyolojik aktivitelerini gösteren çok sayıda kanıt temel alınarak çalışmada, Çaldıran/Van'da yetişen ve halk arasında sıkça tüketilen bazı tıbbi bitkilerin toplam fenolik ve flavonoid miktarlarının belirlenmesi ve farklı organlardan elde edilen su ekstrelerindeki olası biyokimyasal farkların ortaya konması amaçlanmıştır.

\section{MATERYAL ve YÖNTEM}

Araştırma materyalleri olan Alcea pallida, Rumex scutatus, Mentha longifolia, Erigeron acris ve Achillea vermicularis bitkileri Van'ın Çaldıran ilçesinden toplanmıştır. Toplanan örneklerin anatomik olarak teşhisi Van Yüzüncü Yıl Üniversitesi Biyoloji Bölümü öğretim üyelerinden Dr. Fazlı Öztürk tarafından yapılmıştır.

\section{Ekstraksiyon}

Teşhis sonrası örneklerin farklı organları ayrılmış, kurutma kağıdının arasında direk güneş ışığına maruz kalmayacak şekilde kurutulmuştur. Çizelge 1.'de gösterilen bitki kısımları ögütme makinası ile toz haline getirilmiştir. Arazi çalışmalarının yapıldığı dönemlerde, ekstre elde edebilecek miktarda toplanabilen organların analizi yapıldığ bitkilerde tohum, bazılarında ise çiçek kullanılmıştır. Toz haline getirilen örneklere, ağırlıklarının 40-50 katı kadar su ilave edilmis ve $60^{\circ} \mathrm{C}$ 'de bir gece manyetik karıştırıcıda inkübasyona bırakılmıştır. İnkübasyon sonrası ekstreler vakum ile süzülmüş ve $-80^{\circ} \mathrm{C}$ de bir gece bekletildikten sonra liyofilizatör ile suyu uzaklaştırılmıştır. Hazırlanan su ekstreleri total fenol ve flavonoid analizinde kullanılmıştır.

Çizelge 1. Bitkilerin analizde kullanılan kısımları Table 1. The parts used in the analysis of the plants

\begin{tabular}{lll}
\hline Alcea pallida & Çiçek & Gövde \\
& Flower & Shoot \\
Rumex scutatus & Çiçek & Gövde \\
& Flower & Shoot \\
Mentha longifolia & Tohum & Gövde \\
& Seed & Shoot \\
Erigeron acris & Tohum & Gövde \\
& Seed & Shoot \\
Achillea vermicularis & CCiçek & Gövde \\
& Flower & Shoot \\
\hline
\end{tabular}

Toplam Fenolik ve Flavonoid Madde İçeriğinin Belirlenmesi

Ekstrelerde bulunan toplam fenolik madde (TFM) içeriği Singleton ve Rossi (1965)' nin uyguladığ yöntemin 96 kuyucuklu spektrofotometreye uyarlanmış şekline göre belirlenmiştir. Standart olarak Gallik Asit (10, 50, 100, 150 ve $200 \mu \mathrm{g} / \mathrm{mL}$ ) kullanılmıştır. Bu yöntemde ekstre ve standartlardan $20 \mu \mathrm{L}$ mikro plaka kuyucuklarına koyulmuş, 
üzerlerine $100 \mu \mathrm{L}$ Folin reaktifi (1:4) eklenmiş ve pipetajlama ile karıştırılmıştır. Ardından üzerlerine $80 \mu \mathrm{L} \% 10$ 'luk sodyum karbonat eklenmiş ve oda sıcaklığında $30 \mathrm{dk}$ inkübasyon sonrası $750 \mathrm{~nm}$ 'de örnek yerine $20 \mu \mathrm{L}$ etanol içeren köre karşı absorbans okunmuştur. Gallik asit ile oluşturulmuş standart kalibrasyon eğrisi kullanılarak her $1 \mathrm{mg}$ ekstre içinde bulunan toplam fenolik içerik miktarları hesaplanmıştır.

Toplam flavonoid (TF) miktarları, Zhishen ve arkadaşlarının (1999) modifiye edilmiş yöntemine göre belirlenmiştir. Farklı konsantrasyonlarda Kuersetin ve Kateşin $(10,50,100,150$ ve $200 \mu \mathrm{g} / \mathrm{mL}) \% 99.5$ etanol ile çözülmüş ve standart olarak kullanılmıştır. Toplam flavonoid miktarı, Kuersetin'in standart olarak kullanıldığı deneylerde TFQ, Kateşin'in standart olarak kullanıldığı deneylerde TFC ile, kimyasal maddelerin İnglizce dilindeki baş harfleri kullanılarak ifade edilmiştir. Liyofilize ekstre 0.25 , 0.5 ve $1 \mathrm{mg} / \mathrm{mL}$ konsantrasyonlarda olacak şekilde $\mathrm{dH}_{2} \mathrm{O}$ (deiyonize su) ile çözülmüştür. Yönteme göre, 80 $\mu \mathrm{L} \mathrm{dH}_{2} \mathrm{O}$ içeren mikroplaka kuyucuklarına, $20 \mu \mathrm{L}$ standart ve örnek eklenmis, ardindan \%5'lik $\mathrm{NaNO}_{2}$ 'den $6 \mu \mathrm{L}$ kuyucuklara eklenmiştir. $5 \mathrm{dk}$ sonra $6 \mu \mathrm{L} \quad 10 \%$ aluminyum klorür $\left(\mathrm{AlCl}_{3}\right)$ kuyucuklara eklenmiş ve $6 \mathrm{dk}$ sonra $1 \mathrm{M} \mathrm{NaOH}$ 'ten $40 \mu \mathrm{L}$ ilave edilmiştir. Toplam hacim $\mathrm{dH}_{2} \mathrm{O}$ ile $200 \mu \mathrm{L}$ ye tamamlanmıştır. 415 ve $510 \mathrm{~nm}$ 'de abs değerleri elde edilmiş ve toplam flavonoid içeriği $1 \mathrm{mg}$ ekstre içerisindeki flavonoid miktarı olarak, kuersetin ve kateşin eşdeğeri şeklinde hesaplanmıştır.

\section{İstatistiksel Analiz}

İstatistiksel analizler Graphpad Prism 6 kullanılarak gerçekleştirilmiştir. Tüm sonuçlar standart sapmaları (SD) ile ortalama olarak ifade edilmiştir. Analizlerde çoklu karşılaştırmalar grafik oluşturmak için yapılmış ve One-way ANOVA kullanılmıştır. Bitkilerin kendi içlerinde ikili karşılaştırmaları için ise $t$-test kullanilarak, $\quad * \mathrm{p}<0.05, \quad * * \mathrm{p}<0.01, \quad * * * \mathrm{p}<0.001$, $* * * * p<0.0001$ değerleri ile analiz edilmiştir. ${ }^{*} \mathrm{p}<0.05$ istatistiksel olarak anlamlı kabul edilmiştir.

\section{BULGULAR ve TARTIŞMA}

Bitki ekstrelerinin farklı biyolojik etkileri, zengin fitokimyasal içeriklerinden ileri gelmektedir (Hosseinzadeh ve ark., 2015). Fitokimyasal olarak zengin içeriğe sahip bitkilerin sadece insan sağlığ değil, aynı zamanda içeçek, kozmetik, ilaç, gıda sektörlerinde sahip oldukları önem her geçen gün yapılan çalışmalarla ortaya konmaktadır (Rababah ve ark., 2011). Bu nedenle biyolojik aktivite potansiyeli ile bitki ekstrelerinin fitokimyasal bileşimi arasındaki ilişkinin ortaya konması önemlidir.

Çalışma materyallerinin seçimi, arazi çalışmaları sırasında halk ile yapılan etnobotanik görüşmeler neticesinde gerçekleşmiştir. Halkın yörede sıklıkla kullandığı bitkiler önerilmiştir. Fenolik bileşik ve flavonoidler bitki sekonder ürünleridir. Bu ürünlerin bitkilerde üretildikleri ve depolandıkları organlar farklılaşmaktadır. Bitkilerin bulunduğu ortamdaki çevresel koşullar onların fitokimyasal içeriklerini etkilemektedir. Yang ve ark., 2018 yılında yaptıkları çalışmada, önemli bitki sekonder metabolitlerinin (fenolikler, flavonoidler, terpenoidler ve çeşitli biyokimyasal işlemlerden üretilen alkaloidler) ışık, sıcaklık, toprak suyu, toprak verimliliği ve tuzluluk, vb gibi faktörlerden nasıl etkilendiklerini ortaya koymuşlardır. Bu bilgiler ışığında analizde farklı bitki organları tercih edilmiştir. Çalışmada kullanılan bitki organları seçilirken ekstre elde edilebilecek kadar numune toplanabilecek organlar seçilmiştir.

Mevcut çalışmada, total fenolik madde analizi için kullanılan Folin-ciocalteu yönteminde kullanılan gallik asit standart grafiği Şekil 1'de verilmiştir.

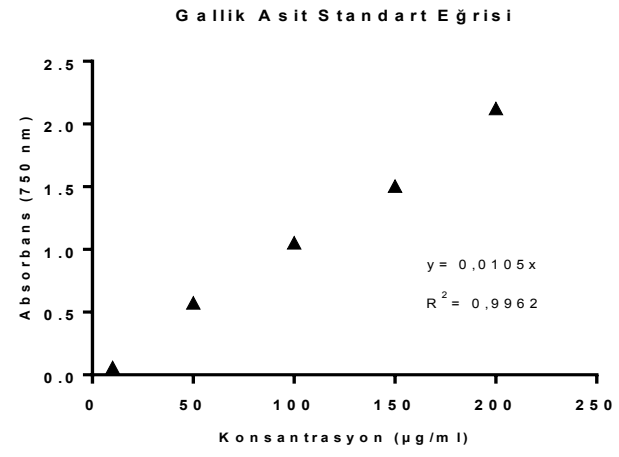

Şekil 1. TFM analizinde kullanılan gallik asit standart grafiği

Figure 1. Gallic acid standard graph used in TFC analysis

Sonuçlara göre, en yüksek fenolik içerik $E$. acris bitkisinin tohum ekstresinden elde edilmiştir (Çizelge 2). Aynı bitkinin gövde ekstresi de fenolik madde açısından zengindir. E.acris halk arasında diş ve eklem ağrılarında kullanılan Asteraceae familyasından bir bitkidir. Bitkinin flavonoidaglikon, luteolin 7-O-glikosidaz, skutellarin, erigerosit içerdiği bildirilmiştir (Yatsyuk ve Regal, 1982). Bu bileşiklerin polifenol olarak antioksidan aktiviteleri dikkate alındığında, E. acris oksidatif stresin neden olduğu hastalıkları tedavi etme anlaminda umut vadetmektedir. $M$. longifolia bütün kıtalarda yayılış gösteren, başlıca içeriği Mentol uçucu yağı olan Lamiacea familyasından bir bitkidir (Gulluce ve ark., 2007). M. longifolia bitkisinin hem gövde hem tohum ekstresinde yüksek fenolik bileşik tespit edilmiştir. Halk arasında antiseptik ve gaz giderisi olarak yahut boğaz ağrıları ve ağız yaralarında kullanılan bu bitkinin (Al-Rawi ve ark., 1988) uçucu yağdan başka fenolik içeriğinin de yüksek olduğu, farmasötik 
etkilerinin olabileceği mevcut çalışmayla ortaya konmuştur. A. pallida bitkisinin gövde ekstresi fenolik içerik bakımından oldukça verimsiz bulunmuştur. $E$. acrisin tohum ekstresi, $A$. pallida gövde ekstresine göre 4 kat daha fazla fenolik içermektedir. Aynı bitkinin çiçek ekstresinin gövdeye göre yaklaşık 3 kat daha fazla fenolik bileşik içermesi bitkilerde sekonder metabolitlerin farklı organlarda depolanma durumu (Babaoğlu ve ark., 2001) ile açıklanabilir.

Çalışmada toplam flavonoid analizi için kullanılan
Kuersetin ve Kateşin standart grafikleri Şekil 2.'de gösterilmiştir.

Kuersetin standart olarak kullanıldığında en yüksek toplam flavonoid miktarı E. acris bitkisinin tohum ekstresinden elde edilmiştir (Çizelge 2).

Marquele ve ark., (2005) E. acris bitkisinin yüksek antioksidan etki sergilediğini ve bunun sebebinin içerdiği polifenoller ve flavonoidler olduğunu bildirmiştir. Çalışmada ortaya konan flavonoid profili bitkiyi tıbbi anlamda önemli kılmaktadır.
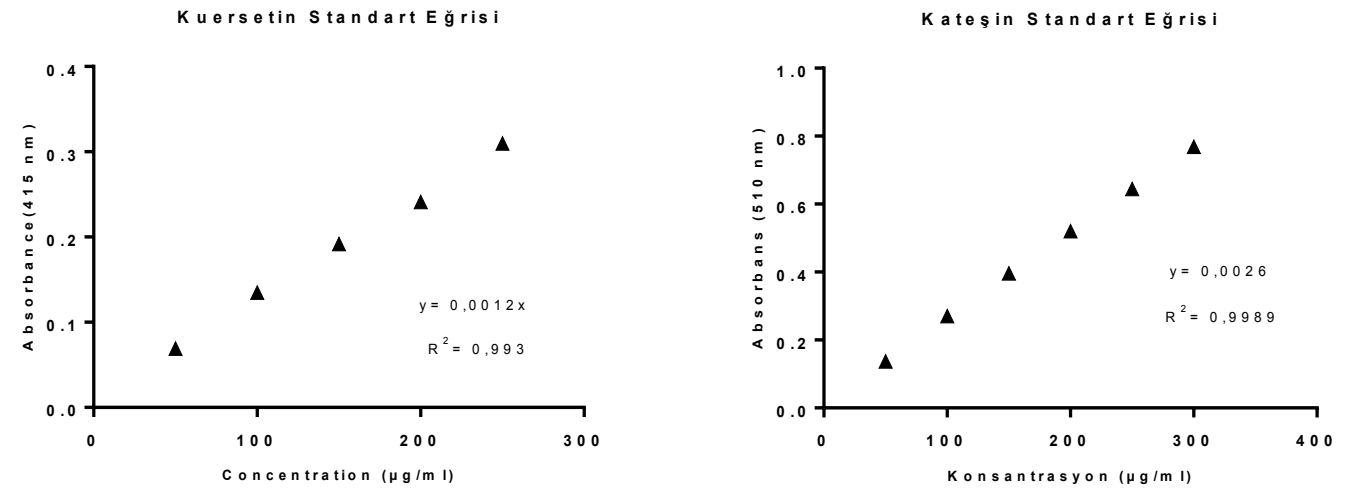

Şekil 2. TF analizinde kullanılan kuersetin ve kateşin standart grafiği

Figure 2. Standard graph of quercetin and catechin used in TF analysis

Çizelge 2. Bitki ekstrelerinin toplam fenolik madde (TFM) ve toplam flavonoid (TF) içerikleri

Table 2. Total phenolic content (TPC) and total flavonoid (TF) of the plant extracts

\begin{tabular}{|c|c|c|c|}
\hline Farklı Bitki Ekstreleri & TFM ( $\mu \mathrm{g}$ GAE/mg) & $\mathrm{TFQ} \pm \mathrm{SD}(\mu \mathrm{g} \mathrm{QE} / \mathrm{mg})$ & $\mathrm{TFC} \pm \mathrm{SD}(\mu \mathrm{g} \mathrm{CE} / \mathrm{mg})$ \\
\hline Different Plant Extracts & $T P C(\mu g G A E / m g)$ & $T F Q \pm S D(\mu g Q E / m g)$ & $T F C \pm S D(\mu g \mathrm{CE} / \mathrm{mg})$ \\
\hline A. pallida (çiçek) & $227.4 \pm 1.475$ & $556.9 \pm 2.406$ & $136.5 \pm 0.8781$ \\
\hline A. pallida (gövde) & $93.71 \pm 1.753^{* * * *}$ & $228.5 \pm 3.825^{*}$ & $45.67 \pm 1.152^{* * * *}$ \\
\hline R. scutatus (çiçek) & $182.7 \pm 0.504$ & $553.1 \pm 4.024$ & $119.9 \pm 1.457$ \\
\hline R. scutatus $(\xi$ & $75.86 \pm 0.4286^{* * * *}$ & $361.5 \pm 3.691^{* * * *}$ & $36.47 \pm 0.8399 * * * *$ \\
\hline M. longifolia(tohum) & $350.7 \pm 0.944$ & $1150 \pm 4.619$ & $263.8 \pm 3.027$ \\
\hline M. longifolia (gövde) & $330.8 \pm 3.997 * *$ & $1074 \pm 4.219^{* * * *}$ & $231.6 \pm 2.91^{* * *}$ \\
\hline E. aceris & $385.3 \pm 4$ & $1453 \pm 2.778$ & $221.8 \pm 1.733$ \\
\hline E. ace & $287.3 \pm 5.229$ & $938.2 \pm 4.589 * * * *$ & $170.7 \pm 0.9741^{* * * *}$ \\
\hline nicularis $(\mathrm{c}$ & $157.4 \pm 2.303^{* * *}$ & $511.5 \pm 2.294$ & $79.94 \pm 0.6894$ \\
\hline A.ve & $127.4 \pm 2.762$ & $359.4 \pm 15.52$ & 2.01 \\
\hline
\end{tabular}

*TFQ (kuercetin eşdeğeri toplam flavonoid), TFC (kateşin eşdeğeri toplam flavonoid) Sonuçlar dört farklı deneyden elde edilen üçlü ölçümlerin ortalamasıdır $(\mathrm{n}=4)$. Karşılaştırmalar aynı bitkinin farklı organları arasında yapılmıştır. ${ }^{*} \mathrm{p}<0.05,{ }^{* *} \mathrm{p}<0.01$, $* * * p<0.001, * * * * p<0.0001$

M. longifolia yüksek flavonoid içeriği ile dikkat çekmektedir (Çizelge 2). Bitkinin insan üriner, intestinal ve solunum sistemi üzerinde hastalık yapıcı bakterilere karşı antibakteriyal etki gösterdiği, bu etkinin içerdiği flavonoidlerden ileri geldiği, özellikle barındırdığı kuercetin-3-O-glikosidin yüksek antibakteriyal etkiye sahip olduğu daha önce rapor edilmiştir (Akroum ve ark., 2009). Çalışmada elde edilen sonuçlar (Şekil 3.) M. longifolia'nın yüksek miktarda flavonoid barındırdığını ortaya koymaktadır. $A$. pallida, $R$. scutatus, $A$. vermicularis bitkilerinin gövde ekstreleri diğer örneklerle kıyaslandığında toplam flavonoid açısından fakir kalmıştır. Gövde ekstrelerinin çiçeğe göre bu denli düşük fenolik ve flavonoid içermesi, bitkinin tüketmek için seçilecek organının farmasötik etkiyi görmede önemini ortaya koymaktadır.

\section{SONUÇ}

Bitkilerin içerdiği fenolik asitler ve flavonoidler insan sağlığını etkileyen önemli aktif bileşenlerdir. Bu bileşiklerin bitkilerde üretildikleri ve depolandıkları organlar farklılaşabilmektedir. Bu nedenle halkın bu bitkileri tüketirken hangi organları tercih etmelerinin 
daha yararlı olacağı mevcut çalışmayla ortaya konmuştur. Yapılan üç analizde de en yüksek değerler $E$. acris ve $M$ longifolia'dan elde edilmiştir. A. pallida, $R$. scutatus, $A$. vermicularis bitkilerinin gövde ekstreleri hem toplam fenolik hem flavonoid açısından $E$. acris ve $M$. longifolia bitkilerine göre oldukça verimsiz olmuştur. Sonuç olarak; $E$. acris ve $M$ longifolia bitkilerinin hem tohum hem gövde ekstrelerinin fitokimyasal profili bu bitkilerin alternatif

tip

değerlendirilebileceğini

ip

uygulamalarında analizler bitkilerin genel içeriklerini tespit amacıyla yapılan bir ön çalışma niteliğindedir. Farklı bitki kısımlarından elde edilen yüksek sonuçlara göre çalışmanın eksik yanını oluşturan sadece spektrofotometrik analizler yapılması da göz önüne alınarak HPLC ve/veya LC/MS/MS ile etken maddelerin tespitine gidilmesi planlanmaktadır.
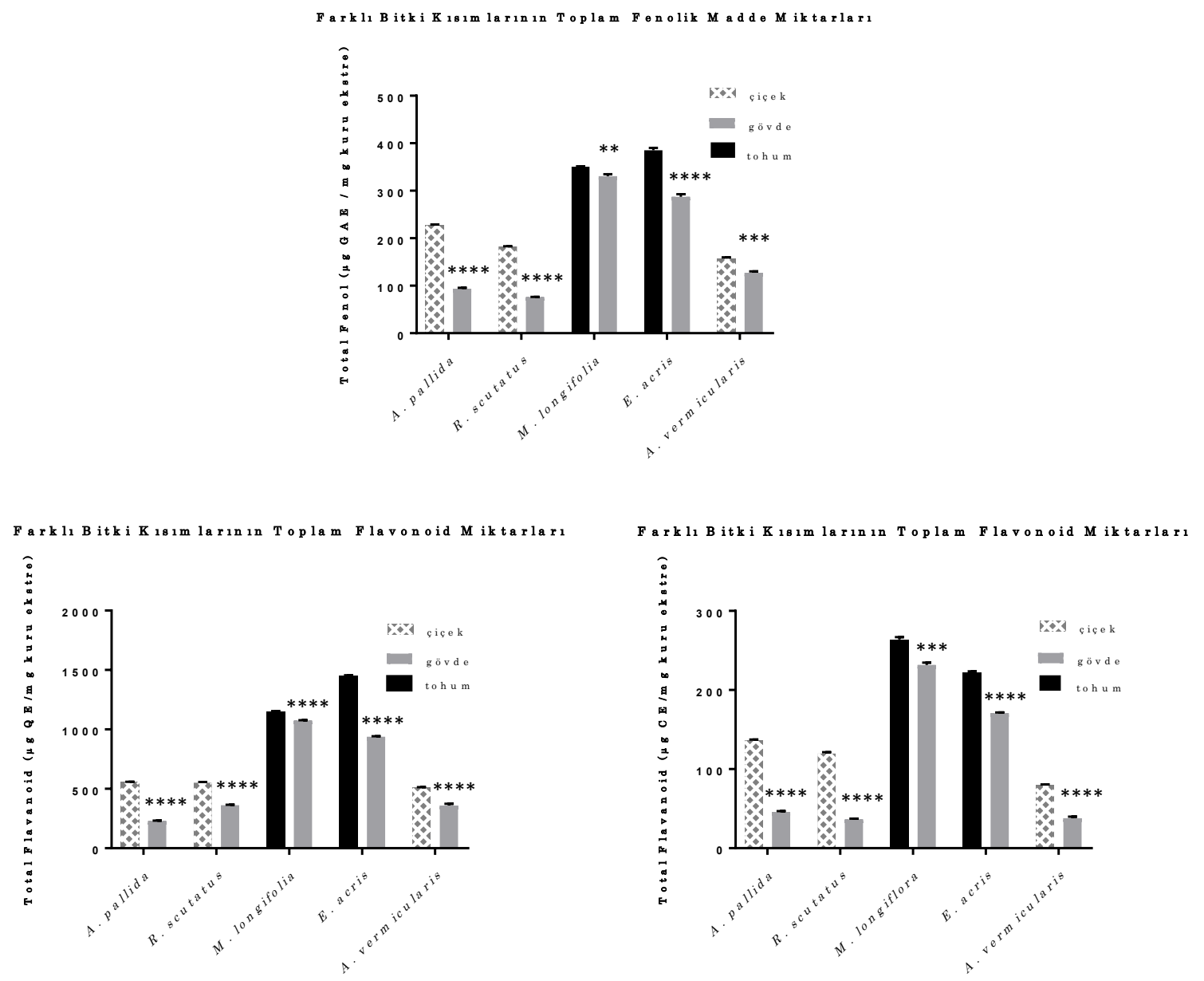

Şekil 3. Farklı organların fitokimyasal analiz grafikleri. Karşılaştırmalar aynı bitkinin farklı organları arasında yapilmıştır. ${ }^{*} \mathrm{p}<0.05,{ }^{* *} \mathrm{p}<0.01,{ }^{* * *} \mathrm{p}<0.001,{ }^{* * * *} \mathrm{p}<0.0001$

Figure 3. Phytochemical analysis graphs of the different organs. The comparisons were made between different organs of the same plant. ${ }^{*} p<0.05,{ }^{* *} p<0.01,{ }^{* * *} p<0.001,{ }^{* * * *} p<0.0001$

\section{TEŞEKKÜR}

Çalışmada kullanılan bitkilerin toplanmasında ve ekstre elde edilmesi çalışmalarında yardımlarından dolayı Moleküler Biyoloji ve Genetik Bölümü 2018 mezunlarından İbrahim Çınardağ, Mazlum Taş, Rengin Özışık, Ceylan Eliş, Bahar Pelda Karadamar ve Elif Sena Şahin'e teşekkür ederiz.

\section{Çıkar Çatışması Beyanı}

Makale yazarları aralarında herhangi bir çıkar çatışması olmadığını beyan ederler.

\section{Araştırmacıların Katkı Oranı Beyan Özeti}

Yazarlar makaleye eşit oranda katkı sağlamış olduklarını beyan ederler.

\section{KAYNAKÇA}

Akroum S, Bendjeddou D, Satta D, Lalauoi K 2009. Antibacterial Activity and Acute Toxicity Effect of Flavonoids Entracte from Menthalongifolia. Am. Eurasian J. Sci. Res., 4: 93-96.

Al-Rawi A, Chakravarty HL 1988. Medicinal Plants of Iraq. Ministry of Agriculture and Irrigation, State 
Board for Agricultural and Water Resources Research, National Herbarium of Iraq, Baghdad.

Araújo JR, Gonçalves P, Martel F 2011. Chemopreventive Effect of Dietary Polyphenols in Colorectal Cancer Cell Lines. Nutr. Res., 31: 77-87.

Babaoğlu M, Ekrem G, Sebahattin Ö 2001. Bitki Biyoteknolojisi I: Doku Kültürü veUygulamaları. Selçuk Üniversitesi Yayınları, Konya, 374s.

Gulluce M, Sahin F, Sokmen M, Ozer H, Daferera D, Sokmen A, Polissiou M, Adiguzel A, Ozkan H 2007. Antimicrobial and Antioxidant Properties of The Essential Oils and Methanol Extract from Menthalongifolia L. sp. longifolia. Food Chem, 103: $1449-1456$.

Hosseinzadeh S, Jafarikukhdan A, Hosseini A, Armand R 2015. The Application of Medicinal Plants in Traditional and Modern Medicine: A Review of Thymus vulgaris. Int. J. Clin. Med, 6: 635-642.

Jamshidi-Kia F, Lorigooini Z, and Amini-Khoei H 2018. Medicinal plants: past history and future perspective. Journal of herbmed pharmacology, 7(1):1-7.

Kumar N, GoelN 2019. Phenolic acids: Natural versatile molecules with promising therapeutic applications. Biotechnol. Rep., 24: 1-10.

Li AN, Li S, Zhang YJ, Xu XR, Chen YM, Li HB 2014. Resources and Biological Activities of Natural Polyphenols. Nutrients, 6: 6020-6047.

Mandlekar S, Hong JL, Kong AN 2006. Modulation of Metabolic Enzymes by Dietary Phytochemicals: A Review of Mechanisms Underlying Beneficial Versus Unfavorable Effects. Curr Drug Metab, 7(6): 661-675.

Marquele FD, Di Mambro VM, Georgetti SR, Casagrande R, Valim YM, Fonseca MJ 2005. Assessment of the Antioxidant Activities of Brazilian Extracts of Propolis Alone and in Topical Pharmaceutical Formulations. J Pharm Biomed Anal, 39: 455-462.

Nakamura Y, Watanabe S, Miyake N, Kohno H, Osawa
T 2003. Dihydrochalcones: Evaluation as Novel Radical Scavenging Antioxidants. Journal of Agricultural and Food Chemistry, 51: 3309-3312.

Rababah TM, Ereifej KI, Esoh RB, Al-u'datt MH, Alrababah MA, Yang W 2011. Antioxidant Activities, Total Phenolics and HPLC Analyses of The Phenolic Compounds of Extracts from Common Mediterranean plants. Nat. Prod. Res. 25: 596-605.

Sankaranarayanan R, Valiveti CK, Kumar DR, Slambrouck S, Kesharwani SS, Seefeldt T, Scaria J, Tummala H, Bhat GJ 2019. The Flavonoid Metabolite 2,4,6-Trihydroxybenzoic Acid Is a Cdk Inhibitor and an Anti-Proliferative Agent: A Potential Role in Cancer Prevention. Cancers, 11(3): 427.

Singh R 2015. Medicinal plants: A review. J Plant Sci., 3(1-1): 50-55.

Singleton VL, Rossi, JA 1965. Colorimetry of Total Phenolics with Phosphomolybdicphosphotungstic Acid Reagents. American journal ofEnology and Viticulture, 16(3): 144-158.

Tungmunnithum D, Thongboonyou A, Pholboon A, Yangsabai A 2018. Flavonoids and other phenolic compounds from medicinal plants for pharmaceutical and medical aspects: An overview. Medicine, 5(3): 93.

Yatsyuk YK, Regal GM 1982. Patent no. SU 914061. Otkrytiya, Izobret., Prom. Obraztsy, TovarnyeZnaki 11: 19. 1982:428588 CAPLUS

Yang L, Wen, K S, Ruan X, Zhao Y X., Wei F. Wang, Q 2018. Response of Plant Secondary Metabolites to Environmental Factors. Molecules, 23(4): 762.

Yang H, Tian T, Wu D, Guo D. 2019. Prevention and treatment effects of edible berries for three deadly diseases: Cardiovascular disease, cancer and diabetes. Critical Reviews in Food Science and Nutrition, 59(12): 1903-1912.

Zhishen J, Mengcheng T, Jianming W 1999. The Determination of Flavonoid Contents in Mulberry and Their Scavenging Effects on Superoxide Radicals. Food chemistry, 64(4): 555-559. 